\title{
Semi-virtual tests of a system using exhaust air, grey water and solar heat for domestic hot water and space heating needs of a multifamily house
}

\author{
Antoine Leconte ${ }^{1}$ and Stéphane Moureaux ${ }^{2}$ \\ 1 Univ Grenoble Alpes, CEA, LITEN, INES, F-38000 Grenoble (France) \\ 2 France Air, F-01708 Beynost (France)
}

\begin{abstract}
This paper presents tests results of a large system on a semi-virtual test bench. The tested system aims to provide the heat needed for domestic hot water and space heating of a building with 19 housing units. The three main thermal sources of the systems are the heat recovery on exhaust air, the heat recovery on grey water and solar thermal collectors. Those sources are combined with a heat pump and terminal auxiliary systems. The core part of the system was set up in the test bench: two $1000 \mathrm{~L}$ storage tanks, a $20 \mathrm{~kW}$ heat pump and the controller of the whole system. This real part interacted with a virtual environment emulating the other parts of the system through hydraulic modules. A realistic test sequence has been defined to study the system operations and to assess its performances. Results are promising and lead to the installation of such a system in a real building.

Keywords: Exhaust air heat, Grey water heat, Solar heat, Domestic Hot Water, Space Heating, Multi Family Houses, Semi-Virtual Tests Bench
\end{abstract}

\section{Background and objectives}

Semi-virtual tests aim to create an interaction between a real system to be tested and a virtual environment, completely controlled and driven by a real-time simulation (TRNSYS in this case). Thus it is possible this way to study the system behavior in various conditions.

The tested system in this paper is a large system that provides heat for Domestic Hot Water (DHW) and Space Heating (SH) needs of a multi-family house with 19 housing units in Strasbourg (France). It is based on 3 heat sources:

- EA: Exhaust air heat recovery (with an air/water heat exchanger).

- GW: Grey water heat recovery (with a grey water buffer store).

- SOL: Solar heat (with solar thermal collectors).

Fig. 1 below globally represents the principle of the system and the tests.

The heat from those sources is stored in central tanks. The source with the highest temperature is used in priority. To do so, temperatures from the solar tank (see Fig. 4 below), the grey water tanks and the exhaust air (see Fig. 8 below) are compared to central tanks temperature (see Fig. 3 for instance).

A Heat Pump (HP) draw the stored energy in order to provide heat at the appropriate temperature for DHW and SH. The HP supplies heat to the DHW tank in priority (see Fig. 5 below): the SH tank is heated up only if the DHW tank temperature is above $50^{\circ} \mathrm{C}$. External classical auxiliary systems give the missing heat if the system can't provide all the needs.

Furthermore, if the temperature of the solar tank is high enough for the needs, solar heat can directly feed up the terminal DHW and SH tanks.

Systems based on grey water or exhaust air to preheat DHW tanks in multi-family house already exists, like the SORAYA® system commercialized by France Air (2018). However, to the knowledge of the authors, there has never been system combining the 3 heat sources mentioned above, for DHW and SH needs. The prototype tested here is probably the first of this kind. 


\section{A. Leconte et. al. / EuroSun 2018 / ISES Conference Proceedings (2018)}

The goal of semi-virtual testing of this system is to study the operation of the core system in near-real conditions and to roughly assess its performances for the Strasbourg climate in order to validate its relevance.

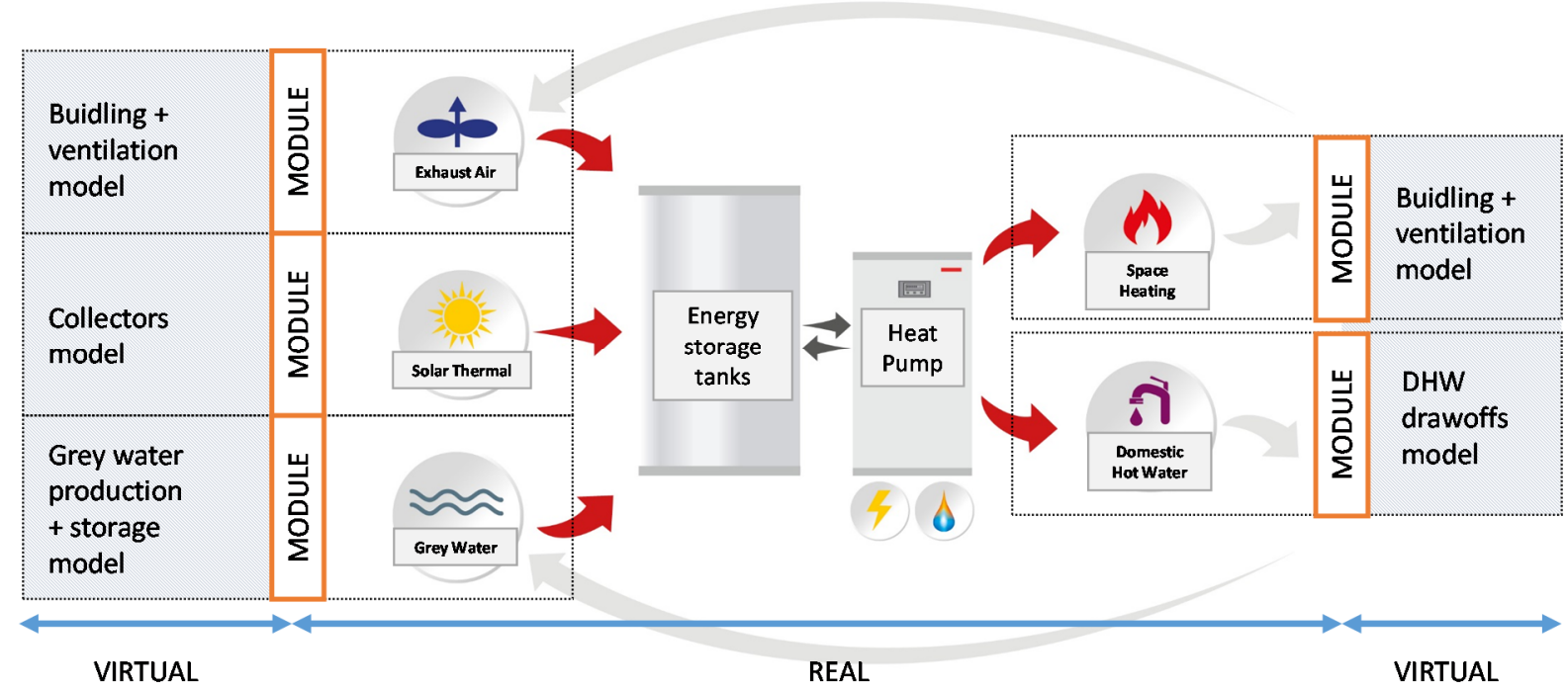

Fig. 1: Global scheme illustrating the principle of the system and of semi-virtual tests

\section{Experimental setup}

For the tests of this system, the core part was set up on the test bench: two 1000L storage tanks, one $20 \mathrm{~kW}$ heat pump and the controller of the whole system. See Fig. 2 for pictures of the setup.
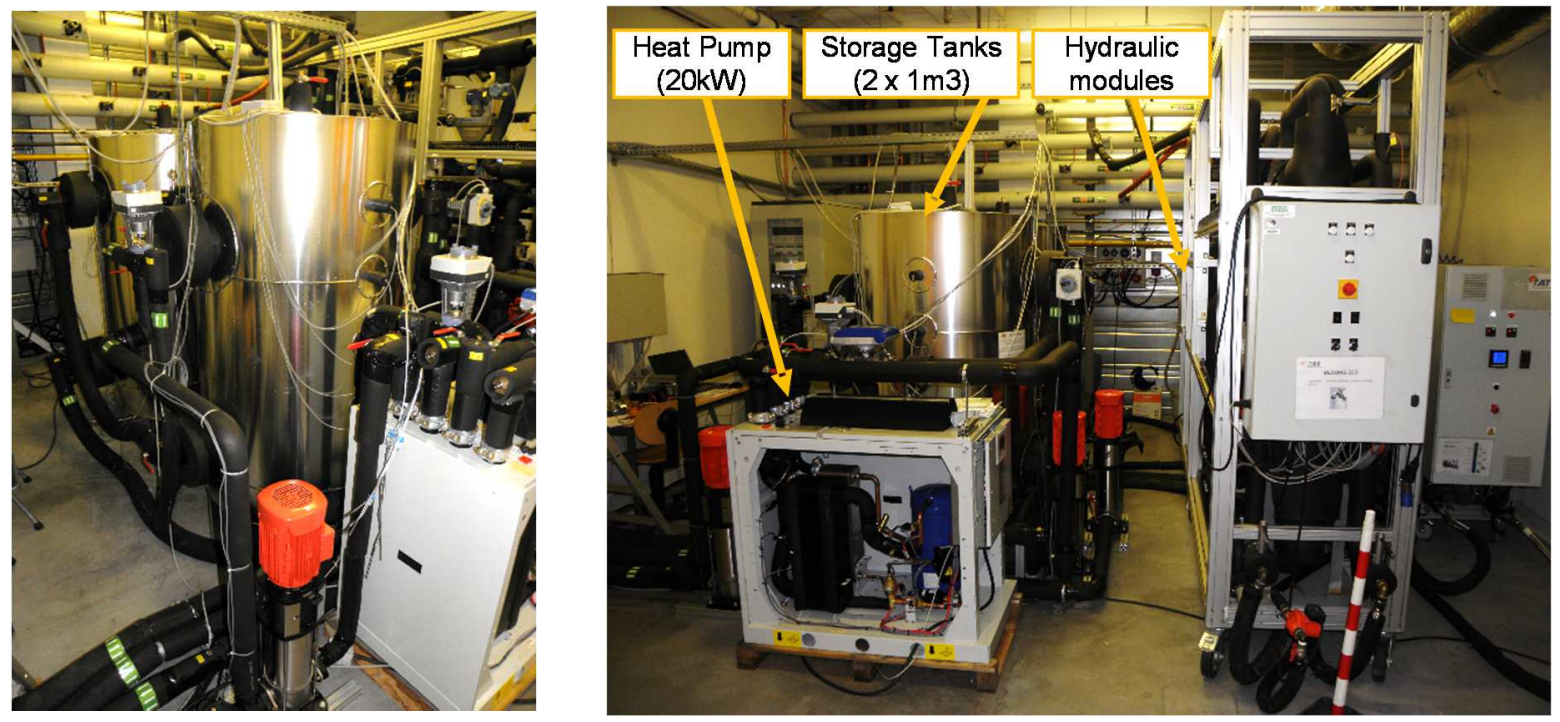

Fig. 2: Pictures of the system tested on the semi virtual test bench

Each hydraulic circuit of the system is connected to modules that reproduce the behavior of the virtual environment as followed:

- At each timestep (1 minute), each module measure the flowrate and the temperature of the fluid coming from the system.

- The values are send to the software that models the virtual environment (TRNSYS in this case, see section 3).

- Based on those values and the assumptions made in the model, the theoretical temperature of the fluid coming back at each circuit is calculated.

- Those results are send as set points to the modules which then provide or withdraw heat from the fluid in order to track the set point temperature. 
- The fluid flows back to the system with the temperatures that it would have had while working with the equipment modeled in the virtual environment.

Hydraulic modules are arranged and combined to meet the power and flowrate specifications of each circuit. The hydraulic diagram and modules specifications are presented on Fig. 3. Considering the foreseen temperature inside the system and for reasons of simplicity, the system was filled with water.

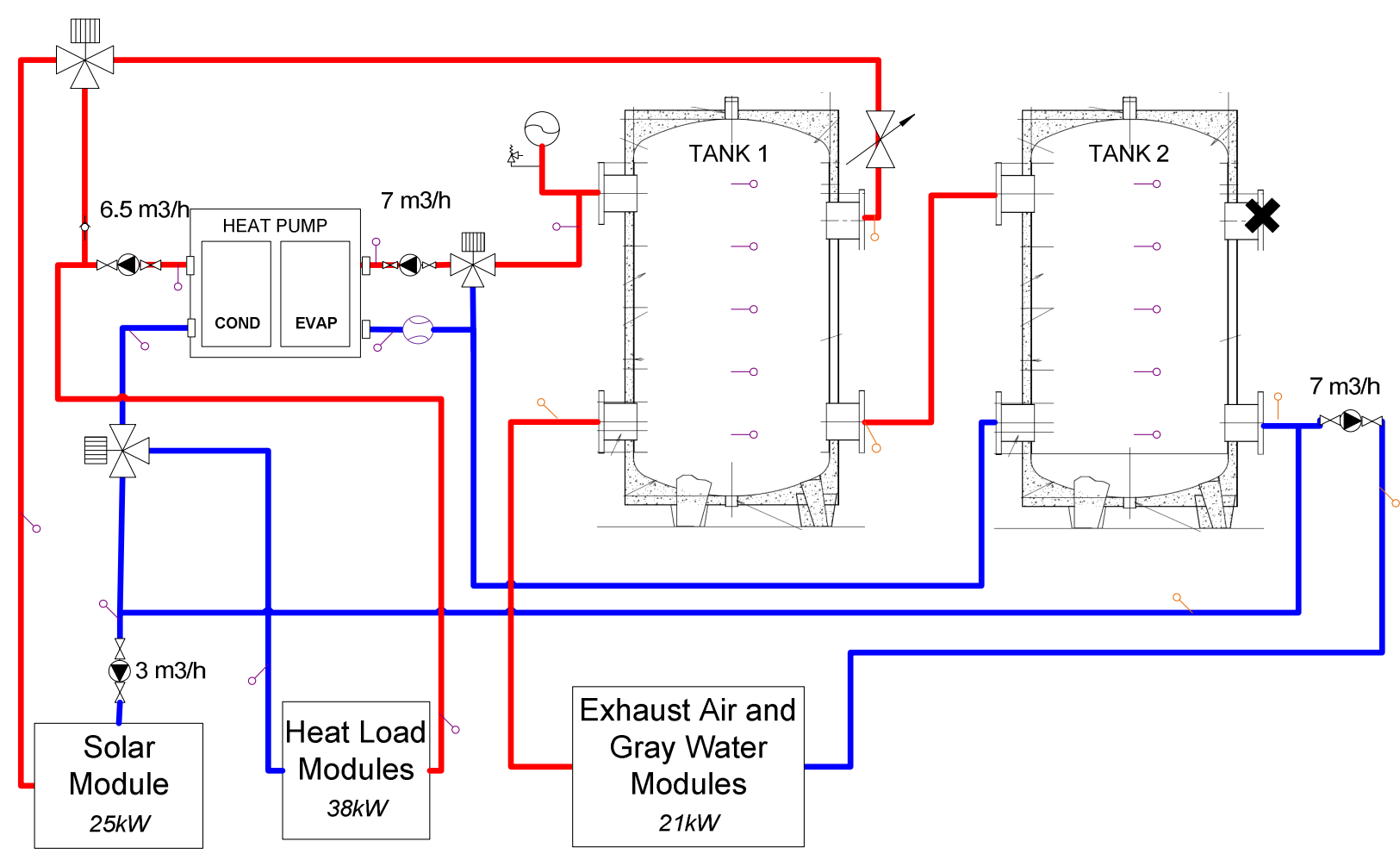

Fig. 3: Hydraulic diagram of the real part of the tested system and modules specifications

Besides, the real controller gathers information from both sides:

- Real measures by its own thermocouples (inside storage tanks and different points of the circuits)

- Measurements from the virtual environment (temperature from additional solar tank and exhaust air for instance) that are reproduced with analog outputs of a resistance box.

Signals and set points from the controller are then:

- Directly transmitted to real actuators (heat pump, pumps, valves)

- Measured and numerically transmitted to actuators of the virtual environment (heat source selection valves and heat load selection valves for instance, see section 3 ).

\section{Definition of the virtual environment}

A detailed TRNSYS model has been developed in order to define the virtual environment of the system during the tests. The goal is to reproduce, through the modules, the behavior of a solar circuit (Fig. 4), the other heat sources circuit (exhaust air and grey water, see Fig. 5) and a heat load circuit (Fig. 8). 


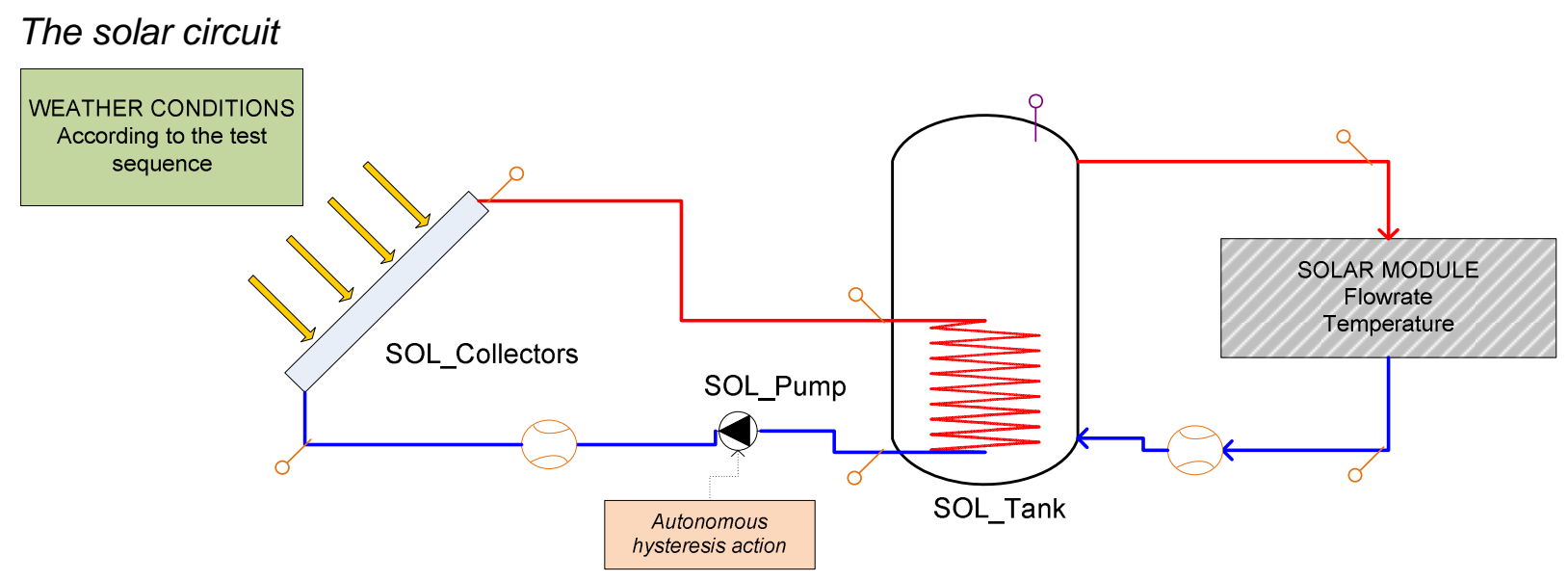

Fig. 4: Hydraulic diagram of the virtual solar circuit

Solar heat is collected thanks to $36 \mathrm{~m}^{2}$ of collectors oriented towards south and tilted of $45^{\circ}$. The performance specification of those collectors are taken from the standard coefficients of the flat plate selective collector defined in the IEA SHC Task 32 (Heimrath and Haller, 2007). The fluid running through the circuit is brine.

A $1.8 \mathrm{~m}^{3}$ tank stores solar heat through an internal heat exchanger, in its lower part, that is characterized by a heat transfer capacity rate of 1800W/K according to (Pelletret R., 1993). The heat losses of the stores are calculated based on the definition of the stand-by heat loss capacity rate in the norm (NF EN 12977-1, 2013).

The heated fluid goes to the system according to the flowrates that are measured on the real setup.

The solar collectors are submitted to the weather variations defined by the selected days (see Section 4). The pump of the collectors loop acts autonomously according to the temperature difference between the collectors and the solar tank (with $[1 \mathrm{~K} 5 \mathrm{~K}]$ as hysteresis thresholds). The fluid flows through the collectors with a fixed flowrate of $1440 \mathrm{~kg} / \mathrm{h}$ when the pump is turned on.

\section{The heat loads circuit}

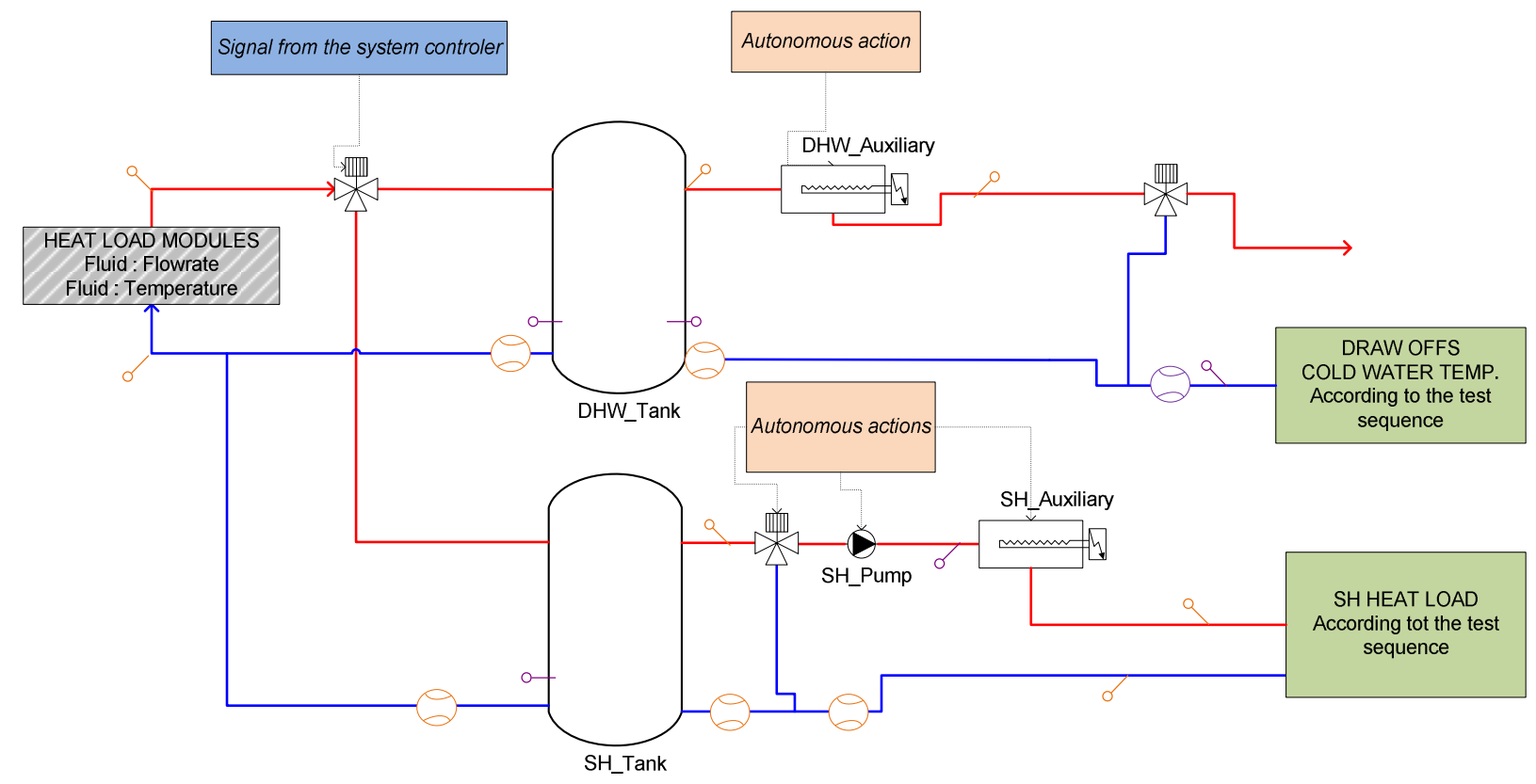

Fig. 5: Hydraulic diagram of the virtual heat loads circuit (DHW and SH)

The heat loads circuit gather the equipment for DHW and SH supplies. The real part of the setup heat up alternately the DHW tank or the SH tanks according to its own controller: the first valve (on the left side of Fig. 5) is oriented in accordance to the controller signals.

The main equipment for the DHW part is a $1 \mathrm{~m}^{3}$ storage tank, a valve that mixes hot and cold water in order to have DHW draw offs at $40^{\circ} \mathrm{C}$ and a theoretical auxiliary system that raises the temperature of the outlet fluid at $40^{\circ} \mathrm{C}$ if needed. As a first simplified approach, neither recirculation loop nor anti-legionella device is considered. 


\section{A. Leconte et. al. / EuroSun 2018 / ISES Conference Proceedings (2018)}

The $\mathrm{SH}$ side is composed of a $1 \mathrm{~m}^{3}$ storage tank, a mixing valve that tracks a heating law and a theoretical auxiliary system that raises the temperature of the outlet fluid if the same heating law is not reached. The heating law is set to have $30^{\circ} \mathrm{C}$ at the heat emitters' inlet when the ambient temperature is $-10^{\circ} \mathrm{C}$. The $\mathrm{SH}$ fluid flows at $3 \mathrm{~m}^{3} / \mathrm{h}$ when there are $\mathrm{SH}$ needs.

The heat load circuit is created to have a model as generic as possible. So, for both sides, the theoretical auxiliary system is considered to be perfect: no heat losses and efficiency of $100 \%$.

DHW needs are derived from the French handbook (ADEME and COSTIC, 2016). The mean daily volume is $2138 \mathrm{~L}$ at $40^{\circ} \mathrm{C}$. A seasonal weight is considered to take into account a seasonal evolution, from 0.72 on day 8 to 1.20 on day 2. The volume is distributed during each day according to a typical MFH draw-offs profile (Fig. 6). The cold water temperature changes every day and is set to the mean temperature of each month suggested for France in the handbook $\left(16^{\circ} \mathrm{C}\right.$ in average over the year).

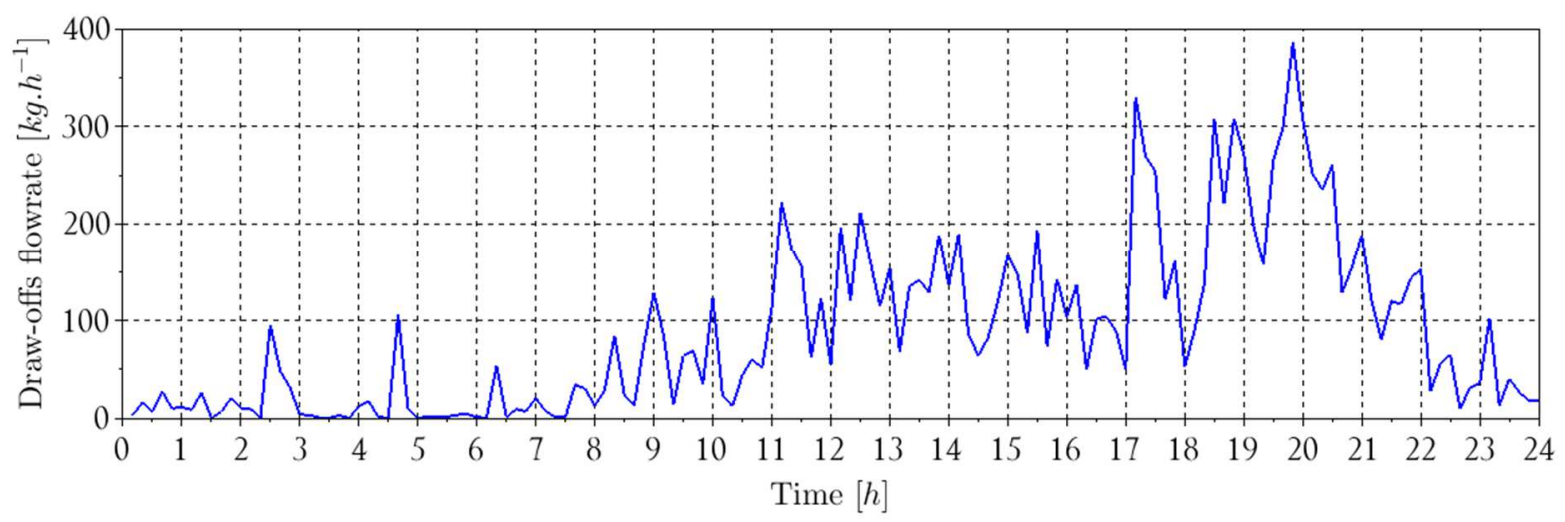

Fig. 6: Reference daily draw offs profile considered in the virtual environment

The SH load profile is defined applying the 12 days climate sequence (see section 4) to the EnergyPlus model of the building that is aimed to host the first prototype of this system (see Fig. 7 below). This building includes 50 housing units. Results are then downsized to fit the test bench specifications (19 housing units).

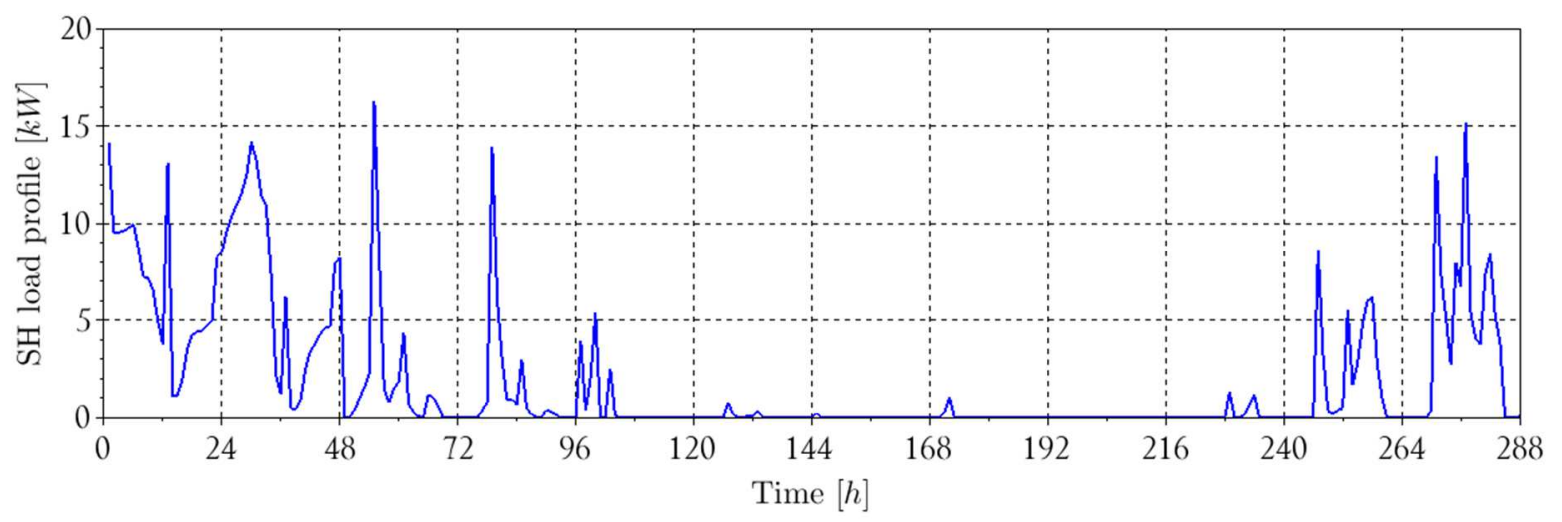

Fig. 7: SH load profile considered in the virtual environment 


\section{The other heat sources circuit}

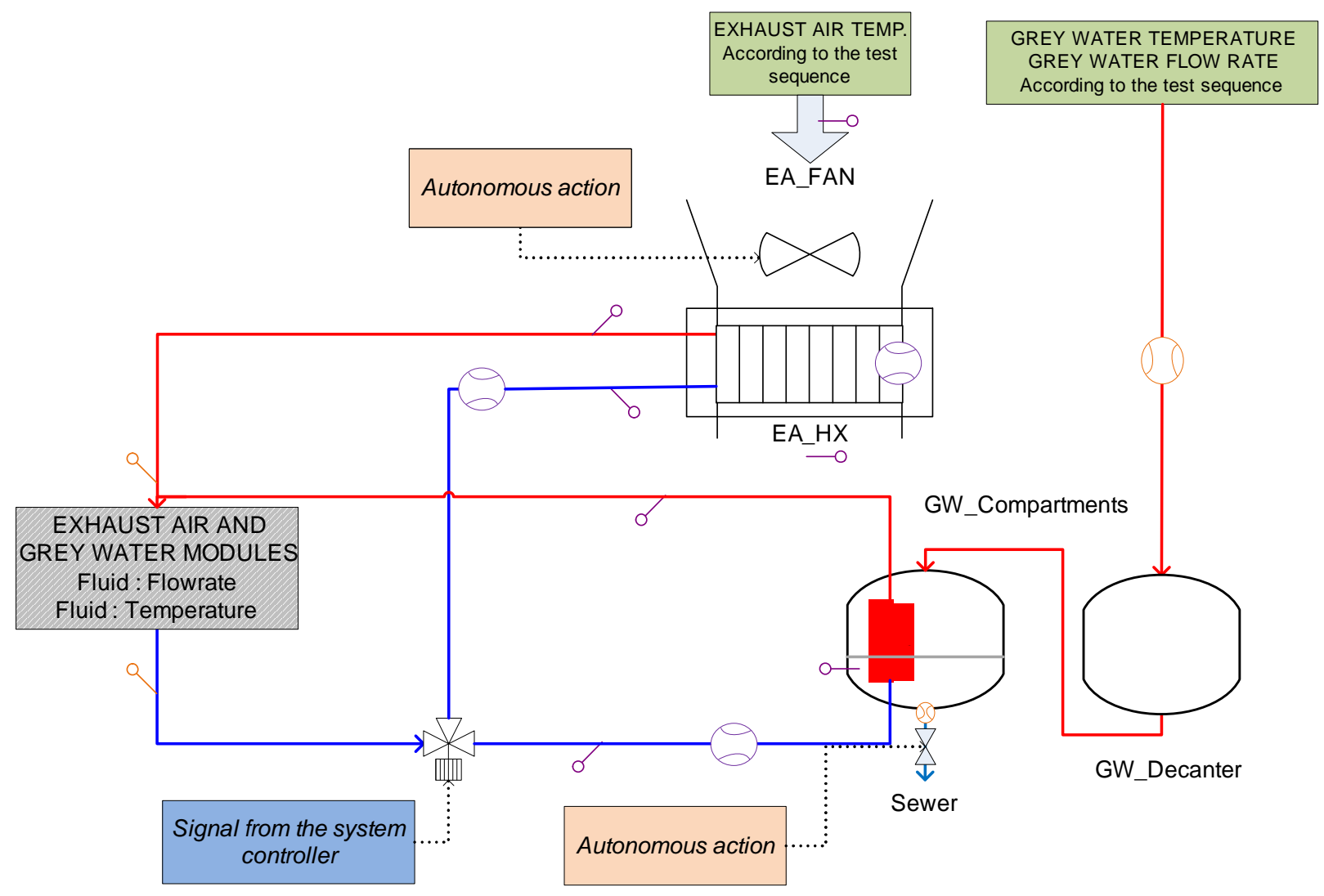

Fig. 8: Hydraulic diagram of the virtual heat sources circuit (Exhaust Air and Grey Water)

The other heat sources enables the real part of the system to withdraw heat alternately from exhaust air flow or gray water tanks. The selection is done according to its own controller: the first valve (on the left side of Fig. 8) is oriented in accordance to the controller signals.

Based on the values of the French thermal regulation for buildings, the total exhaust air of the 19 housing units flows at $844 \mathrm{~m}^{3} / \mathrm{h}$. The heat is withdrawn through a Water/Air heat exchanger that is supposed to be $90 \%$ efficient. The temperature of the exhaust air is taken from the EnergyPlus simulation results, as mentioned above for the definition of SH needs (see results on Fig. 9).

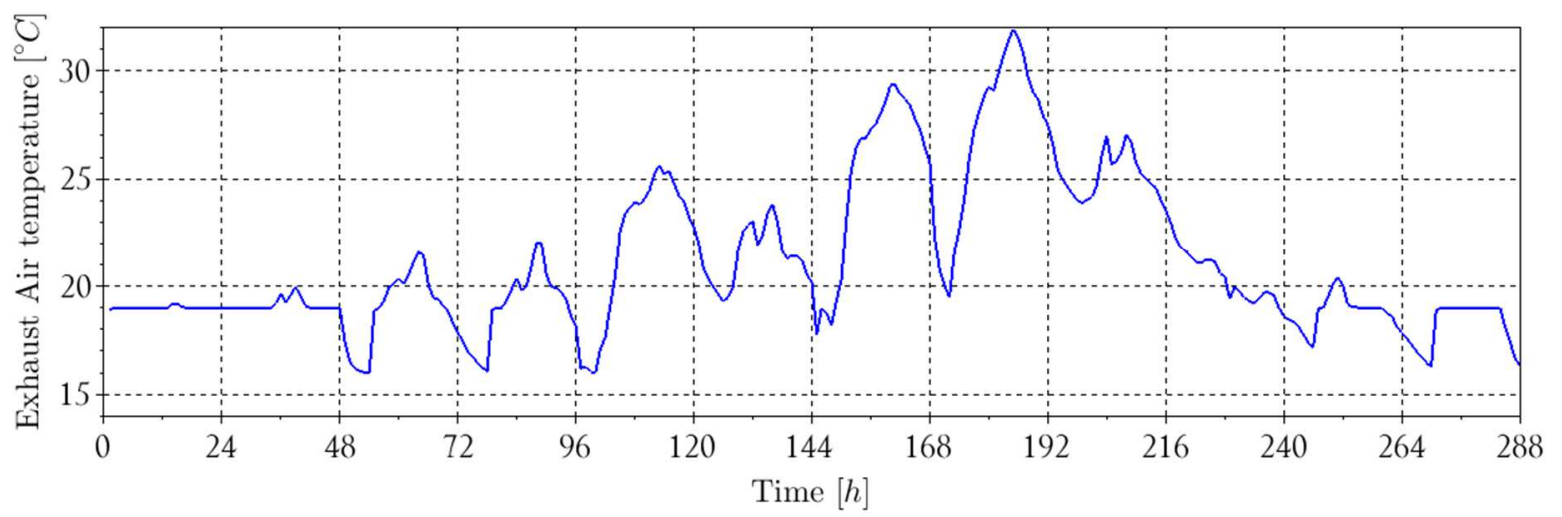

Fig. 9: Exhaust Air temperature profile considered in the virtual environment

The gray water of the building is stored in several tanks with a maximum volume of $0.525 \mathrm{~m}^{3}$ and a total heat loss capacity rate of $11 \mathrm{~W} / \mathrm{K}$. The heat is withdrawn through internal heat exchanger with a maximum heat capacity rate of $908 \mathrm{~W} / \mathrm{K}$. The gray water storage is progressively filled up and flushed once every day. The heat capacity rates are proportional to the filling level of the grey water tanks. According to the expertise of the partners involved in this project, the grey water flowrate is considered as $133 \%$ of the DHW flowrate, at $29^{\circ} \mathrm{C}$. 


\section{Selection of the test days}

During the test, the virtual environment is submitted to weather conditions. So a weather data file had to be created in order to test the whole system. To be appropriate for the objectives of this test, the weather sequence had to be quite short, realistic (with real meteorological evolution), representative of the Strasbourg weather conditions and relevant enough to roughly assess the performance of the system. Thus 12 realistic days had been selected from the Meteonorm weather data file of the "Strasbourg" climate according to the "Short Cycle System Performance Test" method (Albaric et al., 2008).

The SCSPT procedure consists in selecting days from an annual weather sequence in order to make the tested system consume proportionately the same auxiliary energy during the test sequence, as it would consume during a complete year in the same conditions. The selection is based on several simulations of a generic system close to the tested one. The selected 12 days closely matches an annual weather cycle of one precise climate to make the system behave as it usually does over a year.

As a complete generic model of this unusual system has not been developed beforehand, the SCSPT couldn't be properly applied to choose the precise test days for such a system. However, a generic model of a Combisystem with air/water heat pump that provides heat for DHW and SH needs of a Single Family House has been used to select the tests days according to the SCSPT procedure. The modeled system was sized to be proportionately close to the tested system, according to the living area. The selected days for the Strasbourg climate in this case are presented in Tab. 1 below.

Tab. 1: Days selected with the SCSPT method for the Strasbourg climate for a reference Solar Combisystem with air/water heat pump

\begin{tabular}{|c|c|c|c|c|c|c|c|c|c|c|c|c|}
\hline \#Day of the sequence & $\mathbf{1 r}$ & $\mathbf{2}$ & $\mathbf{3}$ & $\mathbf{4}$ & $\mathbf{5}$ & $\mathbf{6}$ & $\mathbf{7}$ & $\mathbf{8}$ & $\mathbf{9}$ & $\mathbf{1 0}$ & $\mathbf{1 1}$ & $\mathbf{1 2}$ \\
\hline \#Day of the year & 20 & 28 & 51 & 88 & 235 & 299 & 184 & 245 & 52 & 309 & 322 & 339 \\
\hline
\end{tabular}

Thus those test days provide realistic weather evolutions that are relevant to analyze the annual behavior of the tested system but the assessed performance in the following sections are only available for this test sequence. The extrapolation of annual performances is not guaranteed here since the method has not been validated for such a system beforehand.

\section{Application of the test sequence and results}

The test sequence has been run for 15 days, with a repeat of the weather data from the $13^{\text {th }}$ day in order to reduce the impact of the initial conditions of the storage tanks on the results.

Firstly the accuracy of the hydraulic modules operations must be assessed. Tab. 2 below represents the global energy difference between the virtual environment and the real system at the bounds of each hydraulic modules. For instance, $-4 \%$ at the "SOLAR" modules means that the module delivered to the real system $4 \%$ less heat than expected by the virtual environment. Those differences are considered acceptable for an appropriate analysis of the system.

Tab. 2: Energy on "virtual" and "real" side of each modules during the test

\begin{tabular}{|c|c|c|c|}
\hline HYDRAULIC MODULES & SOLAR & HEAT LOAD & $\begin{array}{c}\text { EXHAUST AIR AND } \\
\text { GREY WATER }\end{array}$ \\
\hline Energy at the "Virtual" side & $733 \mathrm{kWh}$ & $1216 \mathrm{kWh}$ & $347 \mathrm{kWh}$ \\
\hline Energy at the "Real" side & $705 \mathrm{kWh}$ & $1249 \mathrm{kWh}$ & $335 \mathrm{kWh}$ \\
\hline Global energy difference & $-4 \%$ & $3 \%$ & $-4 \%$ \\
\hline
\end{tabular}

To start the analysis of the system operation, the use of the heat sources (Solar, Exhaust Air, and Grey Water) is presented in Tab. 3 below. For each one of them, a comparison is done between the exploited heat and the maximum heat that could have been collected. The actual collected heat is measured in virtual environments as the heat supposed to be given to the central system. The maximum solar heat collectable is considered as the global solar irradiation on the collector's plane. For the other sources, the maximum heat is calculated considering that all exhaust 
air and grey water were cooled to the minimum reachable temperature in the main stores $\left(11^{\circ} \mathrm{C}\right.$ as set up in the system controller). Results are presented in Tab. 3 below.

Tab. 3: Collected heat and maximum heat for each source during the test

\begin{tabular}{|c|c|c|c|c|}
\hline $\begin{array}{c}\text { HEAT SOURCES } \\
\text { EXPLOITATION }\end{array}$ & SOLAR & GREY WATER & EXHAUST AIR & TOTAL \\
\hline Collected heat & $733 \mathrm{kWh}$ & $231 \mathrm{kWh}$ & $118 \mathrm{kWh}$ & $1082 \mathrm{kWh}$ \\
\hline Maximum heat & $1429 \mathrm{kWh}$ & $715 \mathrm{kWh}$ & $828 \mathrm{kWh}$ & $2972 \mathrm{kWh}$ \\
\hline Energy exploitation rate & $51 \%$ & $32 \%$ & $14 \%$ & $36 \%$ \\
\hline
\end{tabular}

\section{COLLECTED HEAT}

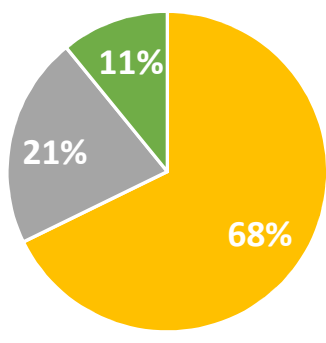

SOLAR

- GREY WATER

EXHAUST AIR

Fig. 10: Share of each source in the global collected heat during the test sequence

As represented by Fig. 10 above, more than 2 thirds of the collected heat is from the solar loop. The solar heat is very well exploited since more than the half of the solar resource is collected. The use of a central heat pump makes the solar heat collected with a quite low temperature level. That increases the solar collectors' efficiency and solicitations. This high global solar efficiency suggests that the collectors' area could even be increased. On the other hand, the other heat sources are less well exploited. Fig. 11 below represents the energy exploitation rates for each day. This figure shows that the use of exhaust air heat and grey water heat is limited by the use of solar heat. In summer days (days 5 to 9), only solar heat is collected. But when no solar heat is available (day 1), more than $70 \%$ of those sources are collected by the system.

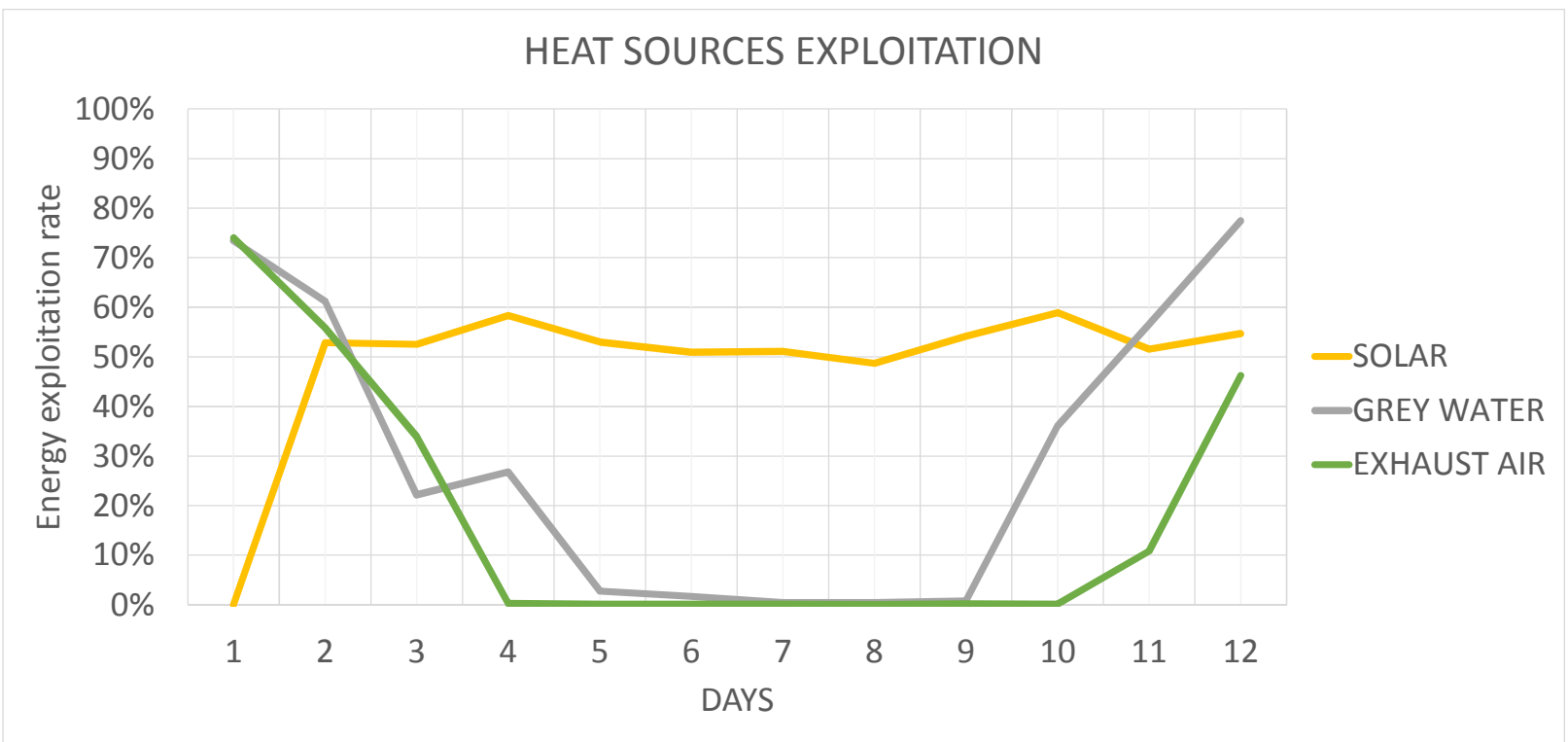

Fig. 11: Evolution of the exploitation rate of each heat source during the test sequence

With the current sizing of the system and its current controller, the solar heat gradually raises the temperature of the central tanks as soon as the heat is available. When tanks temperature is too high (globally above $19^{\circ} \mathrm{C}$ for exhaust air and $29^{\circ} \mathrm{C}$ for grey water), no heat can be collected from the other sources. Fig. 12 below shows that the tanks 
temperature rises up to $30^{\circ} \mathrm{C}$ from the third day thanks to solar heat.

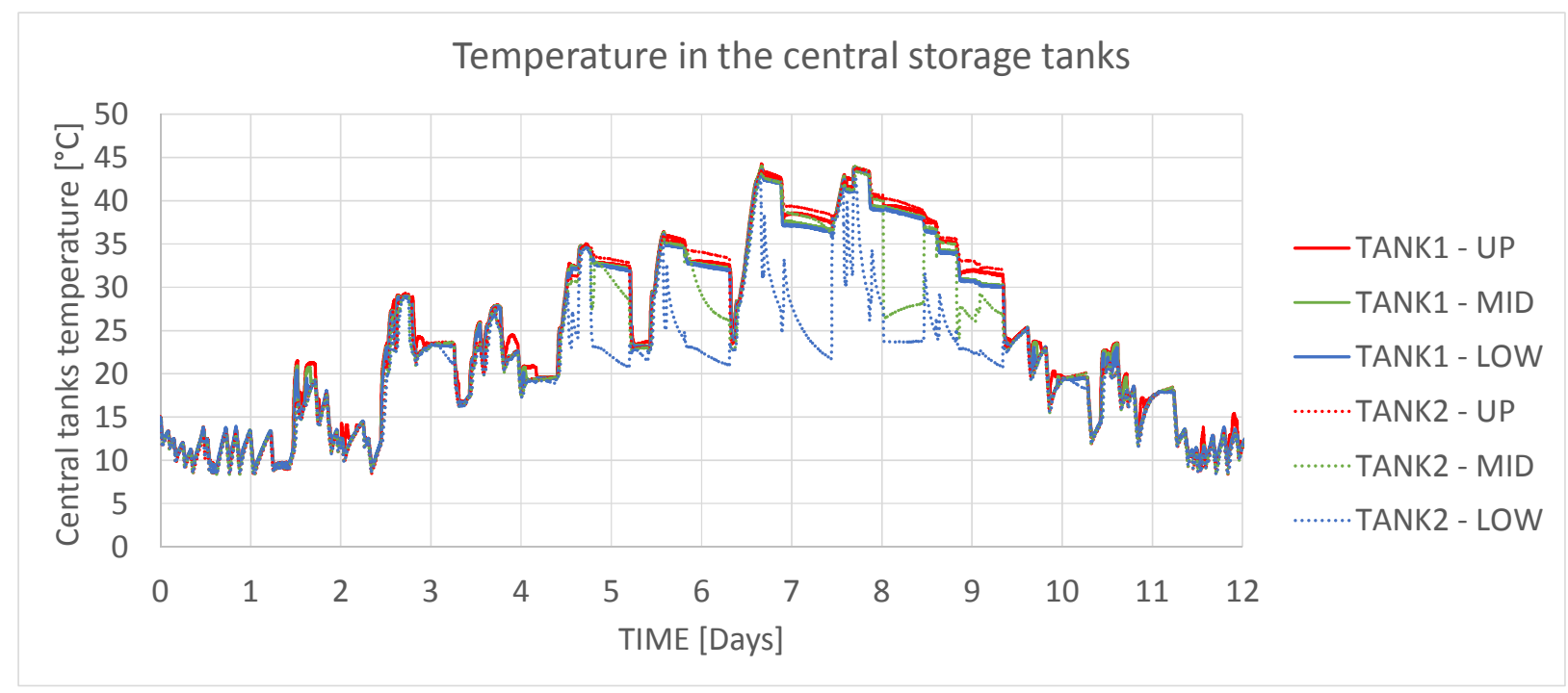

Fig. 12: Evolution of the temperatures measured in the central storage tanks during the test sequence

To complete this analysis, Fig. 13 below shows on the one hand the evolution of the cumulated DHW and SH needs (dotted lines) and, on the other hand, the cumulated energy involved to supply the required needs - i.e. heat collected from the 3 sources (filled area), electricity consumed by the heat pump (dotted area) and theoretical auxiliary energy when the system can't provide the needs (hatched area).

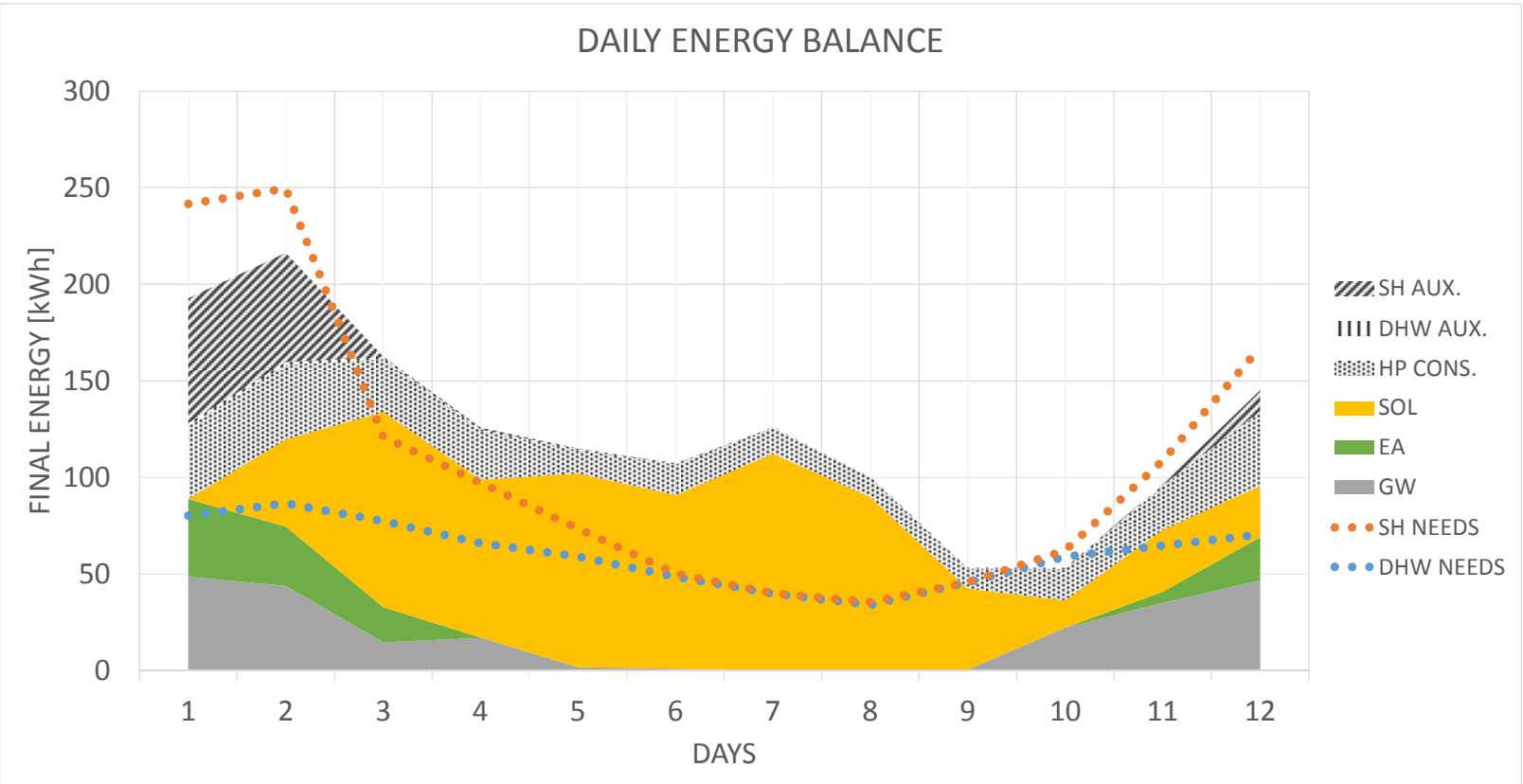

Fig. 13: Daily energy balance during the test

There is a gap between the needs and the global input energy, especially for the first days, that is explained by the initial heat that is stored in the different tanks of the system and the hydraulic modules errors that are a bit larger for these days. The collected heat from the 3 sources during the coldest days, even with a good efficiency, is not enough to meet the energy demand for both DHW and SH. As the heat pump works in priority for the DHW needs, there is almost no need for an external auxiliary in the DHW loop. The SH auxiliary system is mainly requested for days 1 and 2.

Fig. 13 shows also that the heat pump is requested, even for the summer days with a high solar resource. The system with its actual controller collects a large amount of solar heat but with a low temperature level that is raised by the use of the heat pump. Very few energy is transferred directly from the solar loop to the heat loads tanks.

In those conditions, the heat pump is used with a high Coefficient Of Performance (COP): 4.73 over the whole test sequence. Fig. 14 below represents the daily COP measured during the test. 


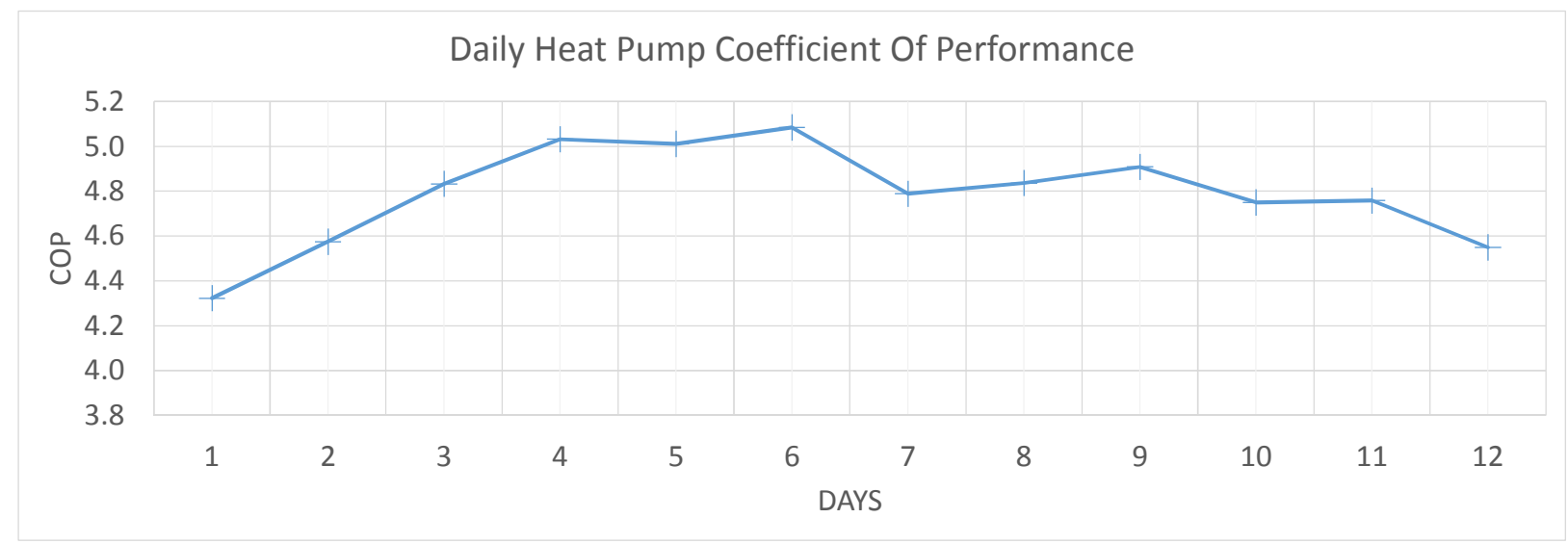

Fig. 14: Daily Heat pump coefficient of performance

Finally, Tab. 4 below focuses on the heat pump consumption, the auxiliary energy and the needs. The heat pump consumption is expressed as a final energy and is split according to its operation mode (SH or DHW mode).

Tab. 4: Final energy consumed by the heat pump and the external auxiliaries compared to the heating needs

\begin{tabular}{|c|c|c|c|}
\hline & SPACE HEATING & $\begin{array}{c}\text { DOMESTIC HOT } \\
\text { WATER }\end{array}$ & TOTAL \\
\hline HEAT PUMP CONSUMPTION & $230 \mathrm{kWh}$ & $39 \mathrm{kWh}$ & $268 \mathrm{kWh}$ \\
\hline EXTERNAL AUXILIARY & $135 \mathrm{kWh}$ & $8 \mathrm{kWh}$ & $143 \mathrm{kWh}$ \\
\hline TOTAL CONSUMPTION & $365 \mathrm{kWh}$ & $47 \mathrm{kWh}$ & $411 \mathrm{kWh}$ \\
\hline NEEDS & $561 \mathrm{kWh}$ & $731 \mathrm{kWh}$ & $1292 \mathrm{kWh}$ \\
\hline
\end{tabular}

On the whole, only $1 \%$ of the heat supplied for DHW needs comes from the theoretical auxiliary. On the SH side, the system can provide $75 \%$ of the heat needed. The other quarter must be provided by an external auxiliary. Considering perfect theoretical auxiliary systems and the global heat pump electrical consumption, the total final energy consumption would represent $32 \%$ of the global needs (see Fig. 15).

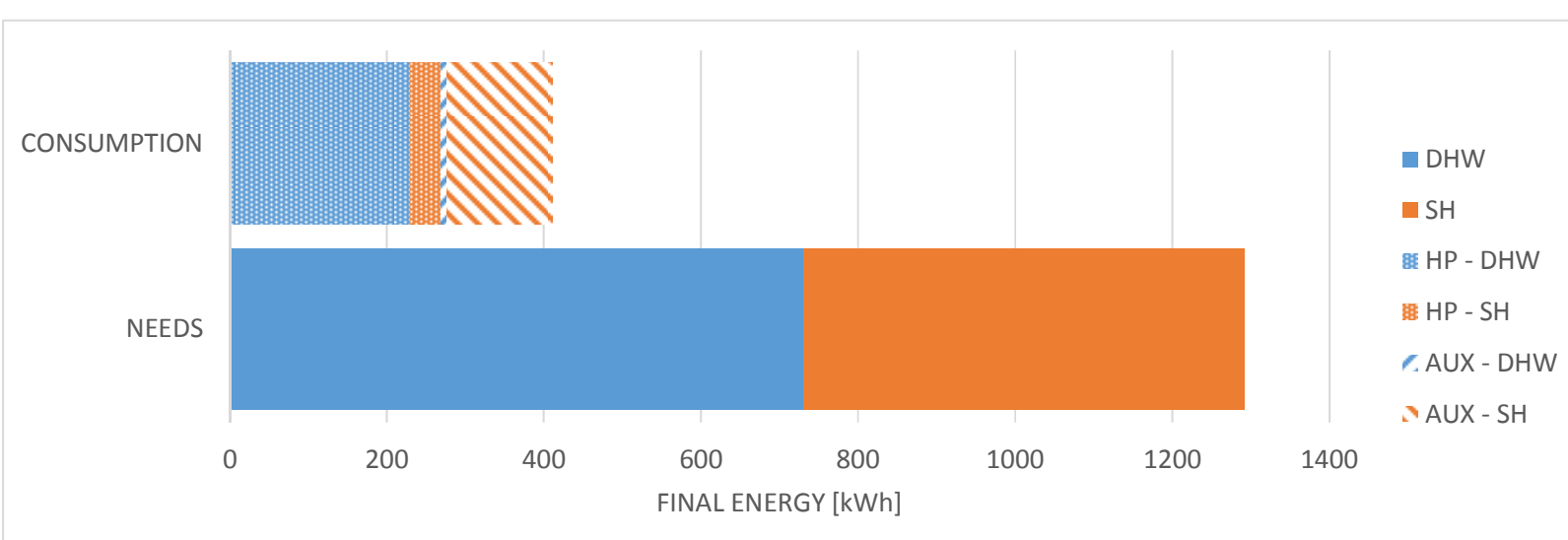

Fig. 15: Comparison between the heating needs and the final energy that would be consumed by the heat pump and the theoretical external auxiliary systems

\section{Conclusion}

A large system based on solar, grey water and exhaust air heat has been set up on a semi-virtual test bench. A 12 days test sequence has been carried on in order to assess the proper functioning of the system.

Based on those tests, the system is deemed relevant and completely operational. The main observations are:

- More than $66 \%$ of the collected heat during the test sequences is from the solar source. Exhaust Air and Gray Water sources are only requested during the coldest days. 
- The heat pump is used with a high Coefficient Of Performance (4.73 over the test sequence).

- Total auxiliary final energy (Heat Pump and theoretical external auxiliary consumption) would represents $32 \%$ of the energy needs.

The observations made through those tests shows also that interesting optimizations can be done like working with higher solar temperatures for instance, in order to favor the use of solar heat directly, and so to avoid the use of the heat pump. That would also leave room for the other heat sources and enhance their exploitation rate.

A larger version of this system will be soon installed on a real multifamily block (50 housing units) in Strasbourg.

\section{Acknowledgements}

This work was supported by the French Agency for the Environment and Energy Management (ADEME).

\section{References}

ADEME, COSTIC, 2016. Les besoins d'eau chaude sanitaire en habitat individuel et collectif - Guide Technique. URL: http://www.costic.com/sites/default/files/upload/telechargements/ECS_MJL_ADEME/besoin-eau-chaudesanitaire-habitat-individuel-et-collectif.pdf (last access: 07/12/2017).

Albaric, M., Nowag, J., Papillon, P., 2008. Thermal performance evaluation of solar combisystems using a global approach. Proceedings Eurosun 2008, October 7-10, Lisbon, Portugal.

France Air, 2018. Système de pré-chauffage ECS-Soraya [On Line]. URL: http://www.france-air.com/secteursdactivite/habitat/habitat-collectif/systeme-de-pre-chauffage-ecs-soraya/ (last access: 27/11/2018).

Heimrath, R., Haller, M.Y., 2007. Project Report A2 of Subtask A : The reference heating system, the template solar system. A report of IEA SHC - Task 32. URL: http://task32.iea-shc.org/Data/Sites/1/publications/task32Reference_Heating_System.pdf (last access: 19/11/2018).

NF EN 12977-1, 2013. Thermal solar systems and components - Custom built systems - Part 1: General requirements for solar water heaters and combisystems.

Pelletret R., 1993. SOLO - Méthode de calcul des performances thermiques des installations solaires de production d'eau chaude sanitaire. CSTB, Valbonne. 